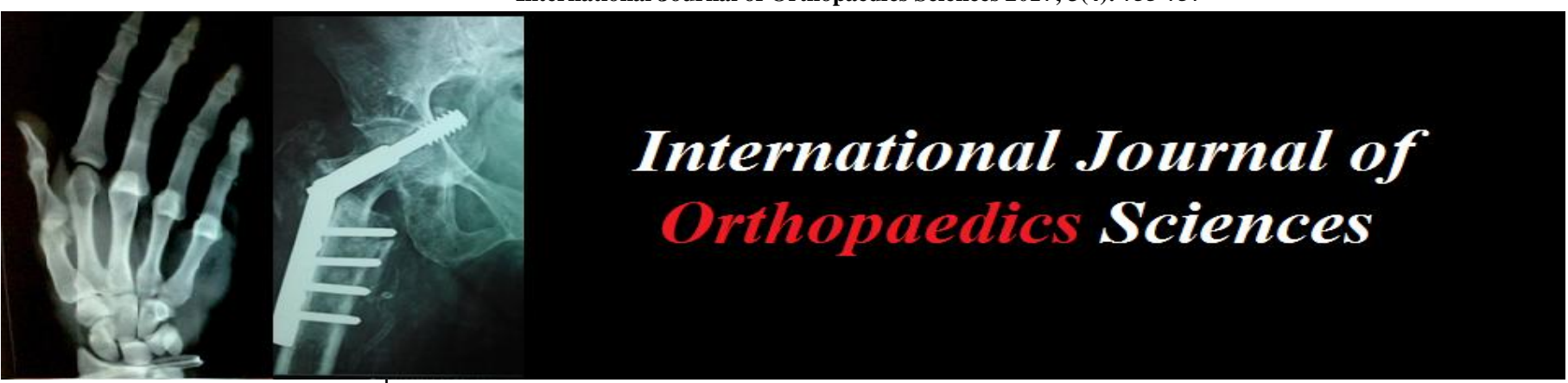

ISSN: $2395-1958$

IJOS 2017; 3(4): 755-757

(C) 2017 IJOS

www.orthopaper.com

Received: 14-08-2017

Accepted: 15-09-2017

Shivashankarappa A

Assistant Professors

Department of Orthopaedic

surgery, JJM Medical College,

Karnataka, India

\section{Prasad NC}

Assistant Professors,

Department of Orthopaedic surgery, JJM Medical College,

Karnataka, India

\section{Pavan P Havaldar}

Associate Professor, Department

of Anatomy, Gadag Institute of

Medical Sciences, Gadag,

Karnataka, India
Correspondence

Prasad NC

Assistant Professors,

Department of Orthopaedic surgery, JJM Medical College,

Karnataka, India

\section{A study on femur neck shaft angle and its clinical importance}

\section{Shivashankarappa A, Prasad NC and Pavan P Havaldar}

DOI: https://doi.org/10.22271/ortho.2017.v3.i4k.104

\section{Abstract}

Introduction: Prevalence of hip osteoarthritis, fracture neck femur and other hip joint ailments are increasing day by day. Arthroplasty is the definite treatment for these patients. The femur forms the skeleton of the thigh, carries body weight, supports the movements of leg and provides attachment to the muscles. Morphology of bones is very much affected by race, sex, environmental factors and life style.

Materials and Methods: 457 femurs were used in present study, femur measurements were collected from different colleges in Karnataka. The measurements of Neck shaft angle, Femoral Length and Neck Length of femur were measured and recorded.

Results: The results of present study are the length of femur was $426.6 \pm 32.76 \mathrm{~mm}$, right femur was $434.3+28.54 \mathrm{~mm}$ and left femur was $418.7+36.14 \mathrm{~mm}$. The neck length femur was $38.8+7.2 \mathrm{~mm}$, right femur was $40.6 \pm 5.3 \mathrm{~mm}$ and left femur was $36.3 \pm 7.1 \mathrm{~mm}$. The neck shaft angle of femur was $138.3 \pm 5.67^{0}$, right femur was $136.2 \pm 4.54^{0}$ and left femur was $140.1 \pm 5.43^{0}$.

Conclusion: The present study observed no significance difference between right and left femur measurements. The present study measurements are may be helpful for orthopaedic surgeons, radiology and anthropological practice.

Keywords: Femur, femoral neck, femoral neck length and femoral neck shaft angle

\section{Introduction}

The transition from quadrupedal to bipedal gait was a considerable biomechanical milestone in the evolution of Homo sapiens. The neck of the femur inclines to form an angle with the shaft. This is wide in infancy when the child learns to walk and gradually decreases during growth. The neck-shaft angle also shows gender difference, smaller in females due to wide pelvis. There is a racial difference owing to the morphology of head, neck and shaft of femur. Normal range of neck-shaft angle varies from $120^{\circ}-145^{\circ}$ with an average value of $135^{0}{ }^{[1,2]}$. The femur is the largest and strongest bone in the body and the structure of its proximal portion allows the leg to move in three dimensions relative to the torso, thus serving as a linchpin of human mobility. Moreover, age related and pediatric disorders at this skeletal site are common and confer strong risk factors for current and future disability. In Orthopedic practice, operations on femur are the most common. Variations in hip morphology are also of critical interest to surgical planning where the ability to take hip morphology into account on a patient specific basis is crucial for success in choosing designs of implants and other structures used for hip replacements and augmentations of hip stability ${ }^{[3,4]}$.

Anatomical study of femur bone serves helpful data to understand different aspect of clinical disease conditions, including common site of fracture, changes in osteoporosis, associated congenital anomalies as well as medicolegal cases. The femur is the longest \& strongest bone in the body. Its length is associated with a striding gait, its strength with the weight and muscular forces which it must withstand. Its shaft is almost cylindrical. It has a proximal rounded articular head projecting medially from its short neck. he femoral neck length is approximately $5 \mathrm{~cm}$ long and connects the head to shaft at an average angle of $135^{\circ}$. This angle facilitates movements at the hip joint, enabling the limb to swing clear of the pelvis ${ }^{[5]}$.

Osteoporosis is generally considered to be a condition affecting women, but up to $30 \%$ of fragility fractures occur in men. The lifetime risk of fracture at the age of 50 years has been estimated to be $20 \%$ for men. Bone mineral density has long been recognised as an important skeleton determinant of fracture risk, but it is becoming apparent that skeletal geometry also 
influences the risk. This has been most extensively studied in women at the hip, in terms of hip axis length, femoral neck axis length, neck shaft angle and femoral neck width. The role of all of these factors as independent predictors of hip fracture risk is controversial in both sexes, with studies giving conflicting results. This uncertainty may have arisen partly because of differences in study design, numbers of patients studied, and also because of wide variations in geometric parameters in different countries and races. Given this variation, it may be necessary to generate data specific to the population under consideration ${ }^{[5,6]}$. The knowledge of the angle of inclination is a valuable aid in the diagnosis and treatment of the fractures of upper end of femur. The length of the femur and stature are of forensic \& anthropological significance. Bony markers such as the head \& neck of femur can be used in determining the femoral length when only a fragment of proximal femur is available $\&$ the required size of length of the neck can be determined to design prosthesis for restoration of normal neck shaft angle. The present study aim is that to find out femoral length, Neck length and Neck shaft angle.

\section{Materials and Methods}

In present study have used 457 femurs (243 right and 214 left) from different colleges in Karnataka. Institutional ethical clearance obtained. The following measurements were measured Neck shaft angle, Femoral Length and Neck Length of femur. Instruments Used for this study are Sliding Calliper, Osteometric Board and measurements measured according to standard anthropometrical method ${ }^{[7,8]}$.

\section{Results}

The results of present study are the length of femur was $426.6 \pm 32.76 \mathrm{~mm}$, right femur was $434.3 \pm 28.54 \mathrm{~mm}$ and left femur was $418.7 \pm 36.14 \mathrm{~mm}$. The neck length femur was $38.8 \pm 7.2 \mathrm{~mm}$, right femur was $40.6 \pm 5.3 \mathrm{~mm}$ and left femur was $36.3 \pm 7.1 \mathrm{~mm}$. The neck shaft angle of femur was $138.3 \pm 5.67^{0}$, right femur was $136.2 \pm 4.54^{0}$ and left femur was $140.1 \pm 5.43^{0}$ (Table $1,2,3$ ).

Table 1: Showing the results of femoral length.

\begin{tabular}{|c|c|c|c|}
\hline \multicolumn{2}{|c|}{ Parameter } & Number & Mean \pm SD(mm) \\
\hline \multirow{4}{*}{ Femoral Length } & Total & 457 & $426.6 \pm 32.76$ \\
\cline { 2 - 4 } & Right & 243 & $434.3 \pm 28.54$ \\
\cline { 2 - 4 } & Left & 214 & $418.7 \pm 36.14$ \\
\hline
\end{tabular}

Table 2: Showing the results of Neck Length.

\begin{tabular}{|c|c|c|c|}
\hline \multicolumn{2}{|c|}{ Parameter } & Number & Mean \pm SD $(\mathrm{mm})$ \\
\hline \multirow{3}{*}{ Femoral Length } & Total & 457 & $38.8 \pm 7.2$ \\
\cline { 2 - 4 } & Right & 243 & $40.6 \pm 5.3$ \\
\cline { 2 - 4 } & Left & 214 & $36.3 \pm 7.1$ \\
\hline
\end{tabular}

Table 3: Showing the results of Neck Shaft angle.

\begin{tabular}{|c|c|c|c|}
\hline \multicolumn{2}{|c|}{ Parameter } & Number & Mean+SD \\
\hline \multirow{3}{*}{ Femoral Length } & Total & 457 & $138.3 \pm 5.67^{0}$ \\
\cline { 2 - 4 } & Right & 243 & $136.2 \pm 4.54^{0}$ \\
\cline { 2 - 4 } & Left & 214 & $140.1 \pm 5.43^{0}$ \\
\hline
\end{tabular}

\section{Discussion}

The neck of femur lies at an angle with the shaft- the neckshaft angle. The angle in the new born is nearly equal to the adult. The average being $126.5^{\circ}$ and range being $106^{\circ}-151^{\circ}$. There is a racial and gender difference, smaller in females when compared to males. The difference in mean femoral length in between populations may possibly be a result of factors affecting bone morphology such as genetic constitution, diet, nutrition status, environment, and physical activity ${ }^{[9]}$.

In present study the length of femur was $426.6 \pm 32.76 \mathrm{~mm}$, right femur length was $434.3 \pm 28.54 \mathrm{~mm}$ and left femur length was $418.7 \pm 36.14 \mathrm{~mm}$. Study of Pandya A M et al study [6] results in agreement with our results, this study mean value of maximum length was higher in male as compared to female. In Pandya A $\mathrm{M}$ et al study for right male bone calculated range was 379.99-523.63mm and for right female bone it was 358.26-476.70mm, according to Pandya A study right femur with maximum length more than $>476.70 \mathrm{~mm}$ can be correctly classified as a male and right femur with maximum length less than <379.99 mm can be correctly classified as a female. According to Pandya if the length is between 379.99 $\mathrm{mm}$ and $476.70 \mathrm{~mm}$, sexing was not possible ${ }^{[10]}$. The present study femur length is correlated with study of Rajeshwari S B. According to Rajeshwari S B, the calculated range for right male was $379.88-523.33 \mathrm{~mm}$ and that for right female it was $358.16-476.80 \mathrm{~mm}{ }^{[11]}$. In study Shakil et al the length of femur was $446.2 \pm 26.39 \mathrm{~mm}$, right femur was $446.6 \pm 26.66$ $\mathrm{mm}$ and left femur was $445.8 \pm 26.12 \mathrm{~mm}^{[12]}$.

The mean femur neck length of study was $38.8 \pm 7.2 \mathrm{~mm}$, the right femur neck length was $40.6 \pm 5.3 \mathrm{~mm}$ and the left femur neck length was $36.3 \pm 7.1 \mathrm{~mm}$. The study of Ravichandran et al results found, the mean femur neck length was $31.88 \mathrm{~mm}$ ${ }^{[13]}$. Our results also in correlation with Siwach RC ${ }^{[14]}$ study in his study the mean femur neck length was $37.2 \mathrm{~mm}$ and minimum effective neck length was $22.6 \mathrm{~mm}$. The mean femur neck length of Shakil et al study was $36.3+4.2 \mathrm{~mm}$, the right femur neck length was $36.1 \pm 4.1 \mathrm{~mm}$ and the left femur neck length was $36.4 \pm 4.3 \mathrm{~mm}^{[12]}$.

The mean Neck shaft angle of present study $138.3 \pm 5.67^{0}$, the right femur neck shaft angle $138.3 \pm 5.67^{\circ}$ and the left was $138.3 \pm 5.67^{\circ}$. Our results are in agreement with Ravichandran et al study, in their study the neck shaft angle was $126.55^{0}[13]$. Our results also in agreement with study of Subhash Gujar, in their study the average neck shaft angle was $136.2^{0}{ }^{[15]}$. In Siwach RC study it was $123.5^{0}{ }^{[14]}$. The mean Neck shaft angle of Shakil et al study $137.1^{\circ}$, the right femur neck shaft angle $137.3^{0}$ and the left was $136.9^{0}[12]$. The morphometric measurements of femurs are helpful in practice of orthopaedic surgery practice during treatment in fractures of femur.

\section{References}

1. Gray's Anatomy, Susan Standring $40^{\text {th }}$ ed., Churchill Livingstone, 1360-1390.

2. Neelima P, Ravi Sunder R, Himabindu A. Study of NeckShaft Angle in Adult Dried Femora Int Jour Heal Scie \& Res. 2013; 6(11):100-102.

3. Lang TF. Proximal femoral anthropometry by computer tomography. In: Preedy VR, editor. Handbook of Antrhropometry: Physical Measures of Human Form in Health and Disease. New York: Springer Science, Business Media, LLC. 2012; 1:756.

4. Dhivya S, Nandhini V. A Study of Certain Femoral Metrics in South Indian Population and its Clinical Importance. International Journal of Scientific Study. 2015; 3(7):132-135.

5. Subhash Gujar, Sanjay Vikani, Jigna Parmar, Bondre $\mathrm{KV}$. A correlation between femoral neck shaft angle to femoral neck length. IJBAR. 2013; 04(05).

6. Khan SM, Saheb SH. Study on neck shaft angle and femoral length of South Indian femur. Int J Anat Res. 
2014; 2:633-5.

7. Singh IP, Bhasin MK. A manual of Biological Anthropology. 1st edi, Kamla Raj Enterprices. 1970.

8. Singh IP, Ekandem GJ, Ani EO. Identification of sex from the head of the femur- demarking points for Calabar, Cross-River State Nigeria. West Afr J Anat. 1986; 1:16-23.

9. Christ Lavelle. An analysis of human femur-Amer Jour of Anat. 1974; 141(3):415-426.

10. Pandya AM, Singel TC, akbari VJ, Dangar KP, Tank KC, Patel MP. Sexual dimorphism of maximum femoral Length. National journal of medical research. 2011; 1(2).

11. Rajeshwari S Bhosale, Dr. Zambare BR. Sex determination from femur using length of femur in Maharashtra. Journal of Dental and Medical Sciences. 2013; 3(4):01-03.

12. Shakil Mohamad Khan, Shaik Hussain Saheb. Study on Neck Shaft Angle and Femoral Length of South Indian Femurs. Int J Anat Res. 2014; 2(4):633635.

13. Ravichandran D. Proximal femoral geometry in Indians and its clinical applications. J Anat. Sco. India. 2011; 60(1):6-12.

14. Siwach RC, Dahiya S. Anthropometric study of proximal femur geometry and its clinical apllication. Indian journal of Orthopaedics. 2003; 37(4):247-51.

15. Subhash Gujar, Sanjay Vikani, Jigna Parmar, Bondre $\mathrm{KV}$. A correlation between femoral neck shaft angle to femoral neck length. IJBAR. 2013; 04(05). 